\title{
Major changes in the Georges Bank ecosystem, 1980 s to the 1990s
}

\author{
David G. Mountain ${ }^{1, *}$, Joseph Kane ${ }^{2}$ \\ ${ }^{1} 2707$ N. Orchard Ave, Tucson, Arizona 85712, USA \\ ${ }^{2}$ Northeast Fisheries Science Center, National Marine Fisheries Service, National Oceanic and Atmospheric Administration, \\ 28 Tarzwell Drive, Narragansett, Rhode Island 02882-1199, USA
}

\begin{abstract}
A major change in surface layer salinity and in zooplankton community structure occurred on Georges Bank between the 1980s and 1990s. Around 1990, salinity began to significantly decrease and the zooplankton community shifted to a greater dominance by smaller sized species. Annual estimates of the number of cod Gadus morhua and haddock Melogrammus aeglefinus eggs hatched on Georges Bank for the years 1979 to 1987 and 1995 to 1999 allowed calculation of a firstyear survivorship index for both species by dividing the number of new recruits from a virtual population analysis by the hatched egg abundance. The survivorship index for each species also exhibited a major shift between the 2 decades, with cod survivorship declining by a factor of 2 from the $1980 \mathrm{~s}$ to the 1990s, and haddock survivorship increasing by about the same amount. The strong trend in (or regime-shift nature of) each of the relatively short physical and biological time series makes establishing statistically significant relationships problematic. However, the co-occurrence of major shifts in all of the parameters suggests that a major change in the Georges Bank ecosystem occurred between the 1980s and the 1990s. Identifying the causes of that change and the mechanisms connecting the different components of the system during that change will require additional analyses and modeling
\end{abstract}

KEY WORDS: Georges Bank $\cdot$ Ecosystem changes $\cdot$ Cod $\cdot$ Haddock $\cdot$ Zooplankton

Resale or republication not permitted without written consent of the publisher

\section{INTRODUCTION}

Georges Bank (GB) is a highly productive, shallow bank that forms the southern boundary of the Gulf of Maine (GoM) (Fig. 1). Historically it has supported large commercial fisheries exploiting the local stocks of cod Gadus morhua, haddock Melogrammus aeglefinus, and other fish species. Implementation of an ecosystem approach to fishery management will require better understanding of how the physical oceanography and the lower trophic levels influence regional fish production. Considerable research has been done during recent decades in the GoM/GB region to gain that better understanding. Here we bring together data and results from some of those previously published studies to identify connections between the physical oceanographic conditions, the zooplankton community, and the production of the GB cod and haddock stocks.
Major changes in the physical water properties and in the biological communities of the GoM/GB region between the 1980s and 1990s have been documented. A large decrease in salinity of the GB waters occurred between the 1980s and 1990s (Mountain 2004), particularly after 1995. This decrease was due to an increase in the inflow of low salinity surface layer waters from the Scotian Shelf to the GoM/GB system and a corresponding decrease in the inflow of warm, saline Slope Water through the Northeast Channel (Smith et al. 2001). The salinity decrease was evident throughout the continental shelf region from the GoM to Cape Hatteras (Mountain 2003). Houghton \& Fairbanks (2001) determined from isotope analysis that the low salinity GB waters originated far to the north from the Labrador shelf. Greene \& Pershing (2007) further suggested that the freshening in the 1990s was ultimately due to an increased export of fresh water from the Arc- 


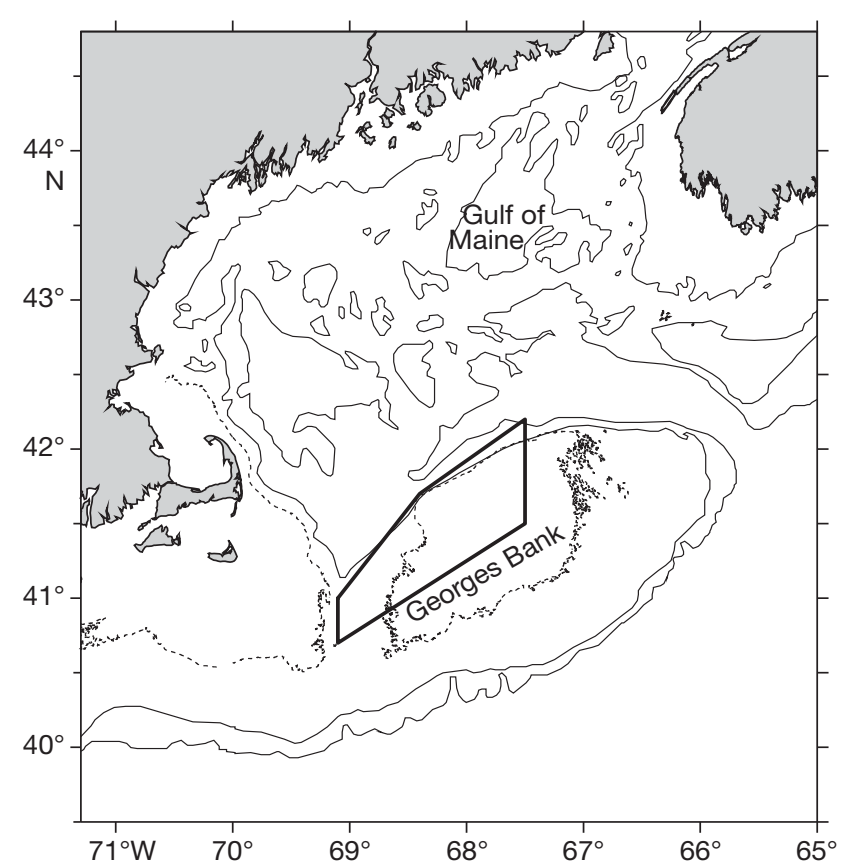

Fig. 1. Georges Bank and Gulf of Maine region. The northwest portion of Georges Bank used in the salinity analysis is indicated by the heavy solid line. Isobaths are 60 (dashed), 100 and $200 \mathrm{~m}$

tic, associated with the rapid changes in the local climate there, that transited in the coastal current system from the Labrador shelf to the GoM/GB region.

The zooplankton community structure on GB also showed a significant change between the 1980s and 1990s (Kane 2007). The latter decade was characterized by an approximate order of magnitude increase in the abundance of smaller copepod species, particularly Oithona spp., Temora longicornis, and Centropages typicus. The abundance of a number of species exhibited significant negative correlations with the salinity of the GB waters over the period 1977 to 2004. Kane (2007) suggested that the shift in community structure was likely associated with the increased inflow of Scotian Shelf water to the GoM system in the 1990s reported by Smith et al. (2001). Within the nearby GoM, Pershing et al. (2005) analyzed continuous plankton recorder (CPR) data and identified many similar changes between the decades, with a lowering of surface layer salinity during the 1990s and a shift in the zooplankton community structure involving many of the same, smaller sized species. The increase in abundance, also by approximately an order of magnitude, for a number of zooplankton species was particularly evident in the winter. Pershing et al. (2005) hypothesized that the low surface salinities promoted stratification of the water column, allowing increased phytoplankton production in winter and leading to the increase in the zooplankton populations.
Cod and haddock on GB both decreased in abundance during the 1980s due to fishing pressure. From 1990 to 2000, the cod stock decreased by an additional $45 \%$, while the haddock stock rebounded and increased in numbers by nearly 5-fold (Brodziak et al. 2006, O'Brien et al. 2006). The recovery of the haddock stock in this period has been attributed largely to stringent management measures implemented in 1994 to reduce haddock fishing mortality, as well as to improved recruitment in some years, particularly in 1998. However, the cod have yet to recover.

The cod and haddock stocks exhibit similar life histories, with peak spawning for both occurring in the spring on the northeast part of GB. The growth and survival of the early life stages of the developing year classes for the cod and haddock populations during the 1980s and 1990s have been the focus of a number of studies. Many of these have been based on the sampling done by 2 programs - the Northeast Fisheries Science Center (NEFSC) Marine Resources Monitoring and Prediction program (MARMAP; Sherman 1980 ) in the late 1970 s to 1980 s and the US GLOBEC GB program (US GLOBEC 1992) during 1995 to 1999. Both programs conducted surveys of the egg and larval populations on the Bank for the developing cod and haddock year classes, providing data that allowed estimates of abundance, mortality, and growth (Lough et al. 2006, Mountain et al. 2008), and the influence of spawning location, water retention/loss on survival, and ultimate recruitment for the 2 stocks (Page \& Frank 1989, Werner et al. 1993, Lough et al. 1994). Of particular interest here are the results of Lough et al. (2006) and Mountain et al. (2008) estimating egg spawning, egg hatching, and larval abundances by year for the MARMAP and US GLOBEC periods, respectively.

Using data and results from the earlier studies, we sought to identify relationships between year-to-year and decadal changes in the physical and biological characteristics of the GB ecosystem: the salinity, zooplankton community structure, and first year survival of the cod and haddock populations on the Bank. While the data are not sufficient to quantitatively investigate the causal mechanisms for the relationships, they do suggest sources for variability in the ecosystem properties.

\section{DATA AND METHODS}

The variation in salinity of the waters on GB was documented by Mountain (2004) for the period 1977 to 2001. The time series has been extended here to 2004 using the same methodology. The average salinity for the 0 to $30 \mathrm{~m}$ surface layer on the northwest part of GB 
(area indicated in Fig. 1) was calculated for all available surveys. A reference annual cycle of salinity was calculated using data from the cruises of the MARMAP program, which conducted routine surveys with fixed station locations for the decade 1978 to 1987 . For all surveys, a salinity anomaly was determined relative to this reference annual cycle. The northwest region of the Bank was used to represent the Bank waters to avoid inclusion of high salinity oceanic waters that occasionally encroach onto the southern flank of the Bank. To compare to the other data sets below, an annual average salinity anomaly was determined by linearly interpolating between the individual survey values and averaging over each year. The survey series began in late 1977, so that 1978 was the first year for which an actual annual average could be calculated, and the data set used here begins in 1978 (Table 1, see also Fig. 2). Overall, observations from 185 cruises contributed to the salinity time series.

To investigate the causes of the salinity changes within the 1980s and 1990s decades, 2 parameters were used to represent local and external sources driving the variability. Monthly Boston precipitation, which co-varies with GoM river input (Mountain \& Manning 1994), was used to represent local forcing. The monthly flow of the St. Lawrence River flow at Quebec City (www.osl.gc.ca/en/runoffs/data/tables. html) was used to represent advective sources of fresh water entering the GoM from the Scotian Shelf. For each decade, following the approach of Mountain \& Manning (1994), the peak correlation between the original, individual survey salinity anomaly values and each forcing series was found with the forcing series averaged over a range of months and lagged a range of months before the time of the salinity values. The averaged, lagged series yielding the highest correlation with the salinity for both forcing terms were entered into a stepwise regression analysis attempting to account for the salinity variability, with a $\mathrm{p}<0.05$ cutoff for acceptance of a term in the regression model. The results are presented in Table 2.

Change in the zooplankton community structure on GB was analyzed by Kane (2007). Zooplankton samples were collected by double oblique bongo net (333 $\mathrm{mm}$ mesh) tows on NEFSC plankton surveys from 1977 to
2004. The abundance (ind. $100 \mathrm{~m}^{-3}$ ) on GB was determined for each taxon. Using data from all years, an annual cycle was calculated for each taxon, and an anomaly for each survey was determined relative to the annual cycle. The anomalies for all surveys within a year were averaged to yield an annual index for each taxon. The 23 taxa whose time series mean was $\geq 500$ ind. $100 \mathrm{~m}^{-3}$, and/or had a percent occurrence of $>25 \%$, were used in the community analysis. The yearly abundance data were classified into groups using hierarchical agglomerative cluster analysis, and non-metric multi-dimensional scaling (nMDS; see Kane 2007 for details). Four groupings of years resulted (see Fig. 3). The majority of years were in 2 major groupings, each containing 11 contiguous years, 1980 to 1990 and 1991 to 2001, with the latter also including 1979. Most of the variation in community structure was in the left-right direction on the nondimensional axes (see Fig. 3). To obtain a single index of the zooplankton community structure for comparison to other parameters, an $x$-coordinate axis, with arbitrary $(-2$ to +2$)$ scaling, was applied to the nMDS

Table 1. Melanogrammus aeglefinus and Gadus morhua. Time series of parameters used in analyses. The 1980 cod egg hatch value in parentheses was not used in the analyses and as a result no recruit per hatched egg (R/hatch) value is presented (see 'Data and methods' for details and for definition of ZooX)

\begin{tabular}{|c|c|c|c|c|c|c|c|c|}
\hline \multirow[t]{2}{*}{ Year } & \multirow{2}{*}{$\begin{array}{l}\text { Salinity } \\
\text { anomaly }\end{array}$} & \multirow[t]{2}{*}{ ZooX } & \multicolumn{3}{|c|}{ - Haddock } & \multirow[b]{2}{*}{$\begin{array}{c}\text { Egg } \\
\text { hatch } \\
\left(\times 10^{12}\right)\end{array}$} & & \multirow[b]{2}{*}{$\begin{array}{c}\mathrm{R} / \\
\text { hatch } \\
\left(\times 10^{-6}\right)\end{array}$} \\
\hline & & & $\begin{array}{c}\text { Egg } \\
\text { hatch } \\
\left(\times 10^{12}\right)\end{array}$ & $\begin{array}{l}\text { Recruits } \\
\left(\times 10^{6}\right)\end{array}$ & $\begin{array}{c}\mathrm{R} / \\
\text { hatch } \\
\left(\times 10^{-6}\right)\end{array}$ & & $\begin{array}{l}\text { Recruits } \\
\qquad\left(\times 10^{6}\right)\end{array}$ & \\
\hline 1978 & -0.07 & -1.52 & & & & & & \\
\hline 1979 & -0.01 & 0.28 & 2.03 & 10.59 & 5.21 & 2.06 & 20.1 & 9.74 \\
\hline 1980 & 0.25 & -0.32 & 2.07 & 7.4 & 3.57 & (33.03) & 41.39 & \\
\hline 1981 & 0.1 & -0.46 & 2.19 & 2.51 & 1.15 & 3.21 & 17.47 & 5.44 \\
\hline 1982 & 0.02 & -0.27 & 0.09 & 3.21 & 35.63 & 0.55 & 9.62 & 17.38 \\
\hline 1983 & -0.17 & -0.66 & 2.38 & 17.57 & 7.38 & 0.88 & 27.39 & 31.27 \\
\hline 1984 & -0.25 & -1.3 & 2.39 & 1.84 & 0.77 & 2.64 & 8.67 & 3.28 \\
\hline 1985 & 0.06 & -1.01 & 1.53 & 15.27 & 9.95 & 2.28 & 42.75 & 18.77 \\
\hline 1986 & 0.15 & -0.87 & 0.98 & 2 & 2.04 & 0.83 & 16.38 & 19.74 \\
\hline 1987 & -0.26 & -0.74 & 2.08 & 17.05 & 8.21 & 0.61 & 23.45 & 38.63 \\
\hline 1988 & -0.2 & -1.17 & & & & & & \\
\hline 1989 & -0.07 & -0.61 & & & & & & \\
\hline 1990 & 0.11 & -0.19 & & & & & & \\
\hline 1991 & -0.13 & 0.31 & & & & & & \\
\hline 1992 & -0.3 & 1.3 & & & & & & \\
\hline 1993 & -0.43 & 1.01 & & & & & & \\
\hline 1994 & -0.11 & 0.47 & & & & & & \\
\hline 1995 & 0.03 & 0.8 & 0.58 & 12.22 & 20.91 & 1.27 & 5.93 & 4.67 \\
\hline 1996 & -0.48 & 0.98 & 1.03 & 25.11 & 24.27 & 1.27 & 10.1 & 7.96 \\
\hline 1997 & -0.43 & 0.94 & 0.7 & 13.72 & 19.5 & 0.37 & 4.58 & 12.28 \\
\hline 1998 & -0.72 & 1.29 & 1.92 & 46.91 & 24.4 & 1.52 & 12.81 & 8.45 \\
\hline 1999 & -0.18 & 0.71 & 1.74 & 18.9 & 10.89 & 0.88 & 7.93 & 8.98 \\
\hline 2000 & -0.02 & 1.35 & & & & & & \\
\hline 2001 & -0.27 & 0.98 & & & & & & \\
\hline 2002 & -0.05 & 0.16 & & & & & & \\
\hline 2003 & -0.09 & 0.09 & & & & & & \\
\hline 2004 & -0.24 & 0.18 & & & & & & \\
\hline
\end{tabular}


output. This series will be referred to as ZooX (Table 1, see Fig. 4).

Lough et al. (2006) estimated annual egg hatching abundance for the GB cod and haddock populations from the ichthyoplankton surveys conducted by the MARMAP program. Generally, the program sampled at about 35 stations on the Bank. Lough et al. (2006) also estimated the annual spawning abundance, egg mortality, and larval mortality (see Lough et al. 2006 for methodological details). The hatching abundance values based on egg survey data (1979 to 1987) are used here (Table 1). The hatching estimate for cod in 1980 is an order of magnitude larger than the other years and appears to be an outlier; this value was not used in the analyses presented here. Similarly, the hatching estimate for haddock in 1982 is nearly an order of magnitude smaller than all other years, and while the value was retained in the analyses, it is noted below that 1982 does appear to be an outlier for haddock in some cases. The GB GLOBEC program conducted monthly surveys of the Bank from February to July in 1995 and January to June in 1996 to 1999. Most surveys included ichthyoplankton sampling at about 80 stations. From the GLOBEC data, Mountain et al. (2008) estimated the annual egg spawning and hatching abundances, and egg and larval mortality rates for the cod and haddock populations. However, they used a somewhat different method to estimate Bank-wide abundance values (kriging, versus the delta distribution used by Lough et al. 2006). For consistency between the data sets, the egg hatching abundance for the GLOBEC years was re-calculated using the methodology of Lough et al. (2006) (P. Berrien pers. comm.; Table 1). The delta distribution can overestimate the sample mean (Syrjala 2000). Mountain et al. (2008) compared the delta distribution, kriging, and a simple $1 / \mathrm{R}^{2}$ weighting interpolation for determining survey abundance and showed that, while the delta distribution estimates were higher by about a factor of 1.7, within each method the relative survey abundance estimates were very consistent.

The annual recruitment for the cod and haddock populations is represented by the number of $1 \mathrm{yr}$ old fish in the following year estimated from a virtual population analysis (VPA). These values were obtained from the NEFSC stock assessment documents for cod (O'Brien et al. 2006) and haddock (Brodziak et al. 2006). An index of first year survivorship for both species was determined by dividing the number of recruits by the egg hatching abundance (Table 1), and expressed as the number of recruits per $10^{6}$ hatched eggs. This measure of survivorship focuses on processes acting during the larval and juvenile stages. It excludes changes in survivorship associated with annual differences in population fecundity and in mor- tality during the egg stage that would be included if VPA spawning stock biomass estimates were used as a measure of reproduction potential. Mortality during the egg stage can vary significantly between years due to differences in wind-driven advective loss from the Bank (Mountain et al. 2008). Normalized anomalies of the recruit per hatched egg (R/Hatch) values in Table 1 were calculated to better compare changes in survivorship between the 2 species. The anomaly values were calculated for each species as

$$
\text { [R/Hatch - mean (R/Hatch)] / SD (R/Hatch) }
$$

with all years being used to determine the mean.

To provide information on the developing year classes of cod and haddock between egg hatching and recruitment, the annual NEFSC fall trawl survey data were used. The fall survey captures young-of-the-year cod and haddock on GB when they are about 6 mo old. Because the fish are small, the catches do not provide a quantitative estimate of the population abundance. However, the young-of-the-year length data were retrieved from the NEFSC database for the 1980s and 1990s to compare the length distributions for the 2 time periods as a possible indicator of differences in growth rate.

\section{RESULTS}

The annual averaged salinity anomaly (Fig. 2) oscillated around 0 from 1978 through 1990, as to be expected given the reference period for the anomalies. From 1991 to 2004, the anomalies were persistently negative, with the largest negative values in 1996 to 1998. In the stepwise regression analysis to identify the sources of the salinity variability (Table 2), the numbers of months to lag and to average for maximum correlation for both forcing terms were plausible and similar between the 2 decades. For the 1980s, the local

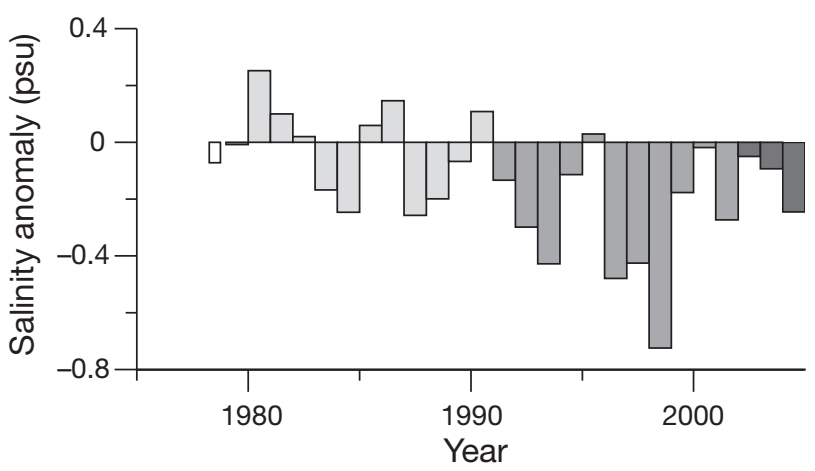

Fig. 2. Annual averaged salinity anomaly (psu) for the northwest part of Georges Bank (see Fig. 1). Bar shading corresponds to the zooplankton groupings in Fig. 3 
Table 2. Stepwise regression analysis for the contribution of Boston precipitation, representing local sources, and the St. Lawrence River outflow, representing distant sources, to the salinity variability on Georges Bank in the 1980s and 1990 s. See 'Results' for details. r: maximum correlation in single-input linear regression; $\mathrm{p}$ : significance of the correlation; $\mathrm{nm}$ : number of months averaged; lag: number of months lagged; \%V: percent of the salinity variance explained by the source term in the stepwise regression

\begin{tabular}{|c|c|c|c|c|c|}
\hline Source & $\mathrm{r}$ & $\mathrm{p}$ & $\mathrm{nm}$ & $\operatorname{lag}$ & $\% \mathrm{~V}$ \\
\hline \multicolumn{6}{|l|}{$1980 \mathrm{~s}$} \\
\hline Boston precipitation & -0.62 & $<0.001$ & 12 & 0 & 38 \\
\hline St. Lawrence River & -0.24 & 0.12 & 8 & 7 & - \\
\hline \multicolumn{5}{|c|}{ Total variance explained } & $38 \%$ \\
\hline \multicolumn{6}{|l|}{$1990 \mathrm{~s}$} \\
\hline St. Lawrence River & -0.63 & $<0.001$ & 14 & 0 & 40 \\
\hline Boston precipitation & -0.48 & $<0.001$ & 8 & 0 & 6 \\
\hline \multicolumn{5}{|c|}{ Total variance explained } & $46 \%$ \\
\hline
\end{tabular}

source (Boston precipitation) accounted for 38\% of the salinity variability, but the advective source (St. Lawrence River) was not significant. For the 1990s, both forcing terms made significant contributions, with the advective source accounting for $40 \%$ of the salinity variance and the local source for $6 \%$. Within the 1980 s, the salinity variability was driven largely by local sources, while within the 1990s, it was driven largely by advective sources, i.e. changes in the inflow of waters from the Scotian Shelf.

In the zooplankton community analysis (Fig. 3), the first major grouping of years (1980 to 1990) corresponds closely to the years of near 0 salinity anomalies, and the second major grouping (1991 to 2001, 1979) corresponds to the period of strong negative salinity anomalies. The ZooX parameter (Fig. 4) shows a step-

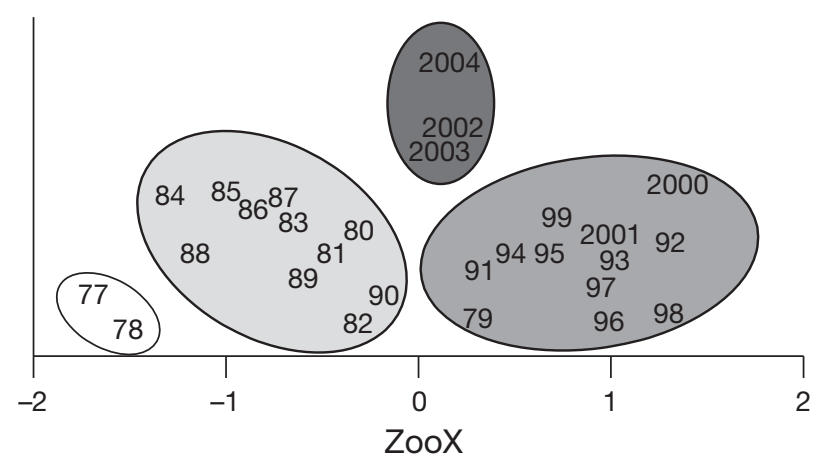

Fig. 3. Results of a multidimensional scaling analysis of the annual zooplankton community structure on Georges Bank, 1977-2004. The encircled groups reflect years strongly grouped by cluster analysis (adapted from Kane 2007); shading corresponds to that in Fig. 2 . An arbitrary linear $X$-coordinate has been added to the original left-to-right nondimensional axis in Kane (2007). This coordinate is identified in the analyses presented here as ZooX

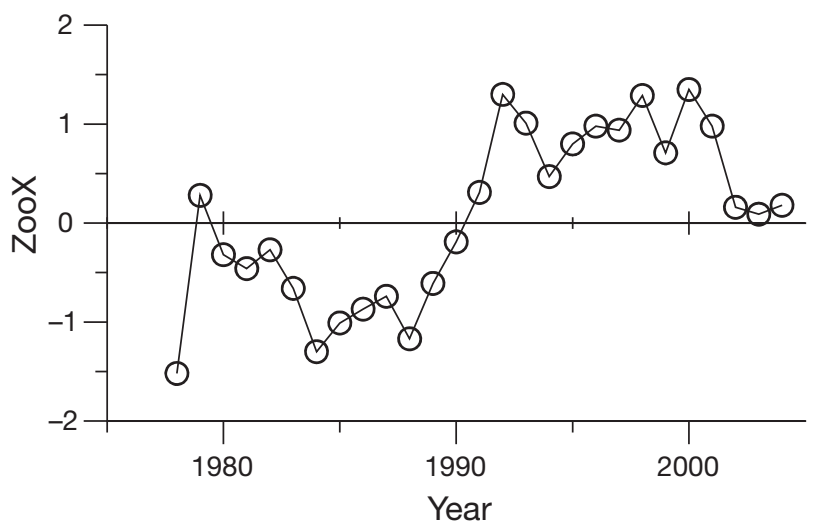

Fig. 4. ZooX parameter (from Fig. 3) vs. year

like transition from low to high values around 1990 to 1991 (reflecting the left-to-right progression through time in Fig. 3). For a comparison between variables in the analyses presented below, 2 groups of years will be considered: 1978 along with 1980 to 1990, when ZooX is < $<$, and 1979 along with 1991 to 2004, when ZooX is $>0$. For ease of discussion, the first group will be referred to as the 1980 s and the second as the 1990s, although each group does contain a few years outside the stated period. Taking all of the data together (1980s and 1990s), the variations in ZooX appear related to variations in the salinity anomaly (not shown, $\mathrm{R}^{2}=0.22$, $\mathrm{p}<0.02$ in a linear regression analysis). However, both series exhibit a substantial trend through the whole time period (e.g. Figs. $2 \& 4$ ), so a regression analysis is not appropriate. After removing the linear trends, the residuals are not correlated $\left(\mathrm{R}^{2}=0.075, \mathrm{p}=17\right)$. More importantly, the relationship between ZooX and the salinity anomaly appears different for the 2 groups of years, which separately do not exhibit a temporal trend (Fig. 5). For the 1980s, the regression has a positive

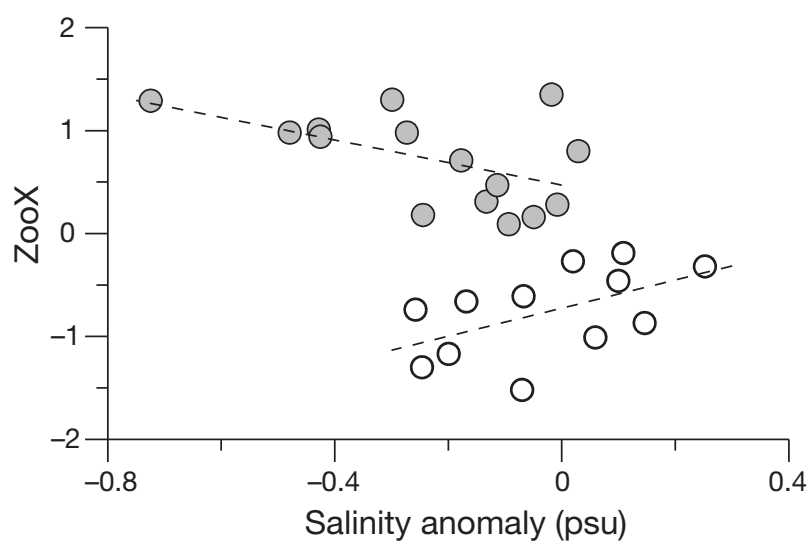

Fig. 5. Comparison of the ZooX (from Fig. 3) and salinity anomaly (psu) parameters. Open (filled) circles: data from the 1980s (1990s) group of years. Dashed lines: linear regression analysis for each group of years (see 'Results' for details) 
slope $\left(\mathrm{R}^{2}=0.29, \mathrm{p}<0.07\right.$; Fig. 5). For the 1990s, the regression has a negative slope $\left(R^{2}=0.27, p<0.05\right.$; Fig. 5).

For all available years (Table 1) the number of haddock recruits shows no obvious relationship to the egg hatching abundance (Fig. 6a). However, looking at the 2 groups of years separately suggests an increase in recruitment with increased egg hatching for both groups, but with different slopes or rates of survival. Although in a regression analysis the haddock egg hatch-to-recruit relationships for both groups are not significant, the 1990s data appear to have a slope or survival rate about 2 to 3 times higher than during the 1980s. For cod, again, no relationship is obvious between recruitment and egg hatching when all years are considered together. For the 1990s group, however, recruitment increases linearly with egg hatching $\left(\mathrm{R}^{2}=0.80, \mathrm{p}<0.02\right.$, slope $=8.8$ recruits per $10^{6}$ hatched eggs). For the 1980 s, cod recruitment initially increases
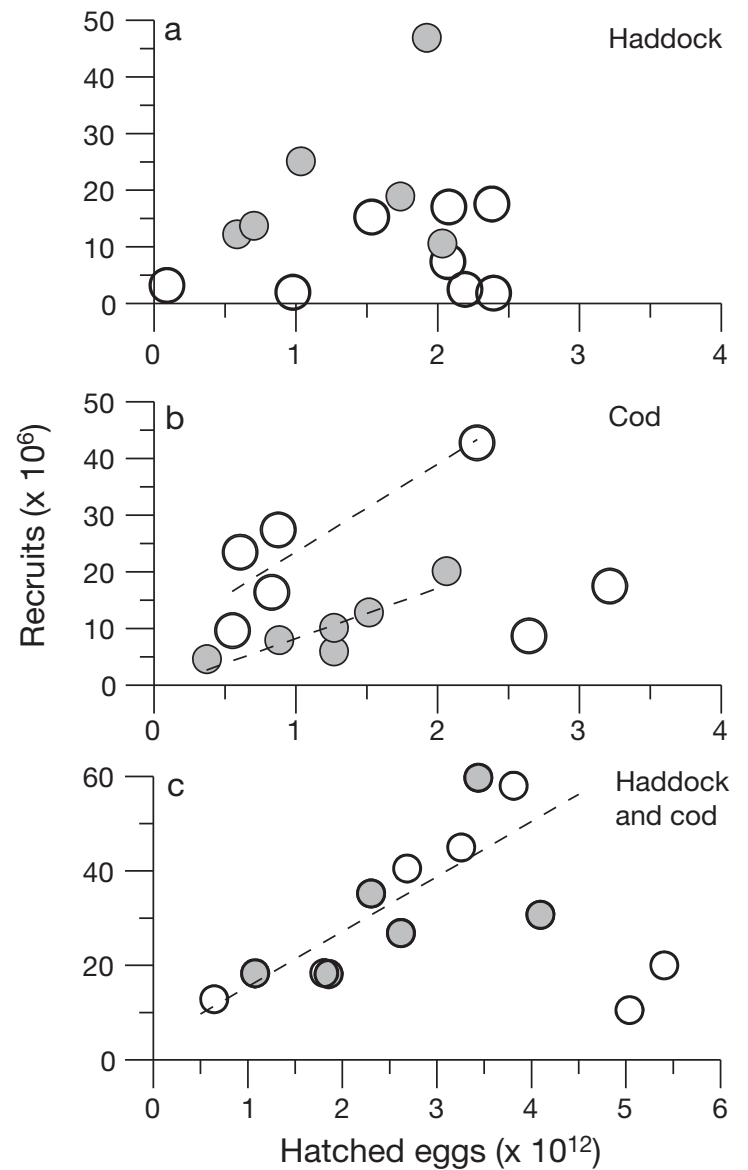

Fig. 6. Melanogrammus aeglefinus and Gadus morhua. Comparison of recruitment and egg hatching abundance for (a) haddock, (b) cod, and (c) combined cod and haddock populations. Open (filled) circles: data from the 1980s (1990s) group of years (see Table 1). Dashed lines: significant linear regressions (see 'Results' for details) with increasing egg abundance before decreasing for the 2 years with the highest hatching abundances (1981 and 1984; Fig. 6b). For hatching values below $2.5 \times 10^{12}$ eggs (i.e. omitting 1981 and 1984), recruitment increased linearly with egg hatching $\left(R^{2}=0.78\right.$, $\mathrm{p}<0.05$, slope $=15.5$ recruits per $10^{6}$ hatched eggs $)$.

Combining the recruitment and egg hatching values for the cod and haddock into a single 'gadid' population, the values for the 2 time periods show a similar linear increase in recruitment for the range of hatching values in which they overlap (Fig. 6c). No year in the 1990s data had a hatching abundance comparable to that in 1981 or 1984 . Taking the rest of the years together, the slope is 11.6 recruits per $10^{6}$ hatched eggs for the combined haddock and cod population $\left(\mathrm{R}^{2}=\right.$ $0.62, \mathrm{p}<0.01)$. The decrease in recruitment in 1981 and 1984 may reflect a density dependence in the survival, as both species had relatively high egg hatching but low recruitment in those 2 years (Table 1). A density-dependent effect could account for the low survival noted above for cod in those 2 years (Fig. 6b). While haddock survival in the 1980s was generally low, 1981 and 1984 had among the highest egg hatching and lowest recruit numbers of any years (Fig 6a, the symbols touching the $x$-axis for hatching values between 2.0 and $2.5 \times 10^{12}$ ), so a density-dependent reduction in survival may have affected haddock as well. The similar survival rate during the 2 time periods for the combined population (Fig. 6c) suggests that the decadal change was a shift in survival between the 2 species within some overall constraint or carrying capacity of the niche they would appear to occupy together.

The shift in survivorship between decades for both species is perhaps better shown by normalized anomalies of the R/Hatch values in Table 1 (Fig. 7). For haddock, the mean anomaly increased from -0.35 in the 1980 s to +0.63 in the 1990 s. The 1982 haddock value appears to be an outlier (>2 SD greater than the mean), likely resulting from dividing by the very low egg hatching estimate (Table 1) noted above. For cod, the mean decreased from +0.35 to -0.55 between the decades. The difference in the means between decades is significant for haddock ( $p<0.03$, including the 1982 value) and marginally significant for $\operatorname{cod}(\mathrm{p}<$ $0.06)$. The difference in means between the species in the 1990s is also significant $(p<0.001)$, but in the 1980s, the difference is significant only if the 1982 value for haddock is dropped $(\mathrm{p}<0.02)$. The larger variability in the anomaly values for both species during the 1980s, as compared to the 1990s, is likely due to the MARMAP program having only about half the number of stations on GB as did the GLOBEC program.

The shift in first year survival for the cod and haddock populations occurred between the same time 


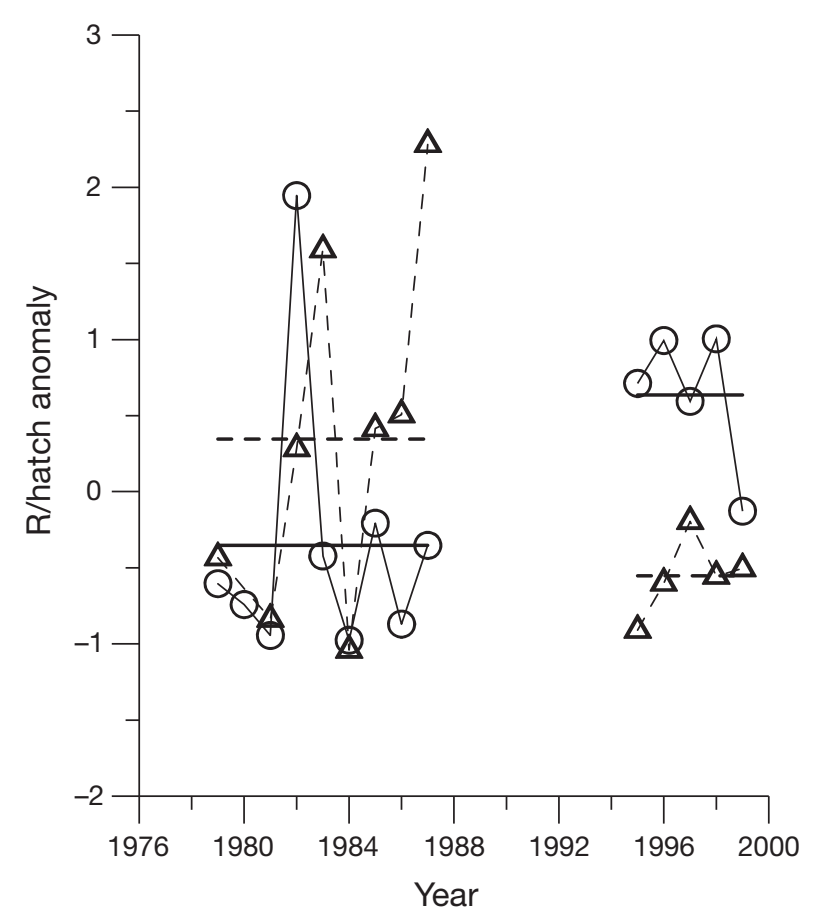

Fig. 7. Melanogrammus aeglefinus and Gadus morhua. Normalized anomalies of recruit per hatched egg (R/hatch) for haddock (circles and solid lines) and cod (triangles and dashed lines). Heavy horizontal lines: mean anomaly value for each species in the 2 decades

periods that the zooplankton community structure exhibited a step-like change (Fig. 4). The yearly survivorship for cod decreased as the ZooX index of the zooplankton community structure increased (Fig. 8a; $\mathrm{R}^{2}=0.55, \mathrm{p}<0.01$, excluding 1981 and 1984). The 2 years noted earlier where a density-dependent reduction in survival may have occurred do not follow this trend. For haddock, the yearly survivorship increased as the ZooX index increased (Fig. 8b) with the exception of the 1982 apparent outlier $\left(R^{2}=0.58, p<0.003\right.$, excluding 1982). As noted earlier, the 1981 and 1984 values for haddock fall within a period when haddock survivorship was generally low and ZooX was negative, so a possible density-dependent reduction in survivorship would not be obvious in the figure.

\section{DISCUSSION AND CONCLUSIONS}

The data indicate major changes or shifts in the salinity, zooplankton community structure, and first year survivorship for the cod and haddock populations on GB. The decadal shifts from the 1980s to the 1990s in salinity and the zooplankton have been documented previously (Mountain 2004, Kane 2007). The changes in first year fish survivorship are reported here for the first time. The similar timing of the changes suggests

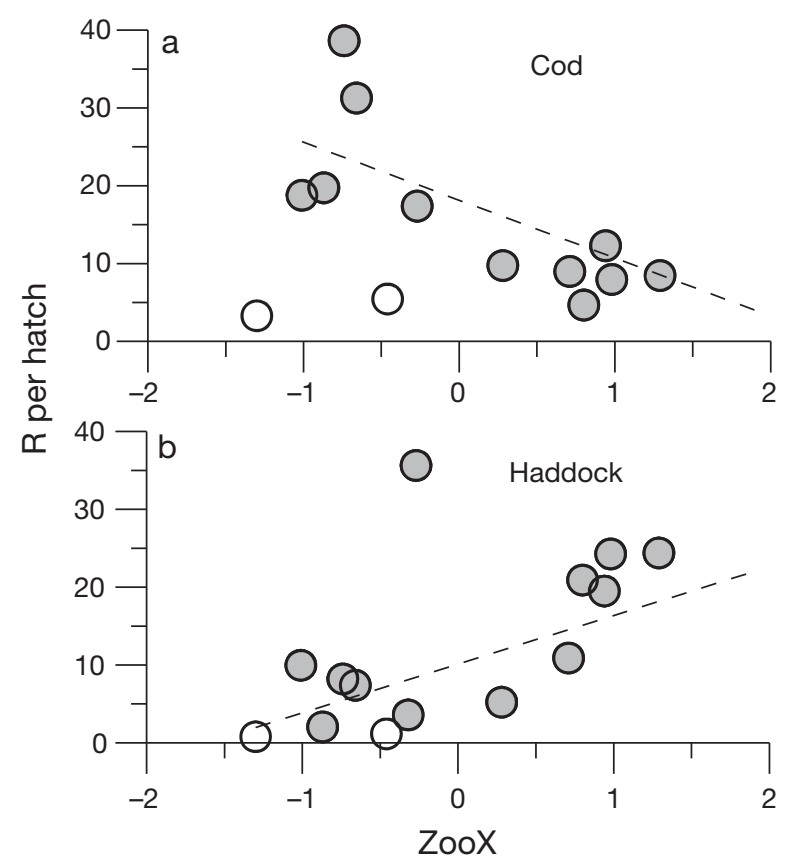

Fig. 8. Melanogrammus aeglefinus and Gadus morhua. Comparison of (a) cod first year survivorship (recruits per $10^{6}$ hatched eggs) and ZooX (from Fig. 3), and (b) haddock first year survivorship and ZooX. The 2 open circles represent the 1981 and 1984 values. Dashed lines: significant linear regressions (see 'Results' for details)

causal relationships between these components of the Bank's ecosystem, with salinity changes having influenced the zooplankton community, which in turn influenced fish survival. However, the shortness of the time series and the apparent regime-shift nature of the changes, particularly for the zooplankton (Fig. 4) and the fish survivorship (Fig. 6), make establishing significant statistical connections between the parameters problematic. Only the egg hatching-recruitment relationship for the combined cod and haddock populations (Fig. 6c) did not exhibit a temporal shift or trend through the time series. The primary characteristic of interest is the co-occurring shift in the various parameters, which appears as a single event around 1990. The relationships between parameters before and after the shift are similar in some cases, as for zooplankton and fish survivorship (Fig. 8) and different for others, as for salinity and zooplankton (Fig. 5).

Identification of plausible mechanistic connections linking changes in 1 parameter to those in another would add credibility to the assumption that the identified relationships are causal in nature and not just cooccurring. A single mechanistic connection linking the changes in the GB salinity and in the zooplankton community structure, both within and between the 1980s and 1990s decades, is not obvious. A shift in zooplankton community structure similar to that observed on 
GB was also evident over the same time period in the GoM (Pershing et al. 2005), indicating that the change occurred throughout the region. The salinity variability also was observed throughout the GoM/GB region (Mountain 2004). Meise-Munns et al. (1990) showed that the changes in copepod populations on GB from 1977 to 1984 were more closely related to the changes in the same populations in the western GoM than to environmental conditions on the Bank itself, suggesting that the copepod changes were advected onto the Bank by the characteristic circulation pattern and not caused by biological responses to the local conditions on the Bank. In a similar manner, the zooplankton community shift around 1990 may have originated in the GoM and been advected onto the Bank. The 1990s freshening greatly affected the upper layer stratification and winter mixing/convection in the western GoM (Taylor \& Mountain 2009), which likely would have affected the timing of the spring phytoplankton bloom. Durbin et al. (2003) attributed greater winter stratification associated with low salinity surface water observed in February 1999 to causing a strong, early phytoplankton bloom and increased productivity/ abundance of many of the smaller zooplankton species identified by Kane (2007) and Pershing et al. (2005). Using satellite data for the period 1998 to 2006, Ji et al. (2007) showed that the spring bloom in the Scotian Shelf/GoM region generally occurred earlier with lower surface layer salinities.

The primary cause of the decrease in the mean salinity on GB between the 1980s and 1990s was a change in the inflows to the GoM system (Smith et al. 2001) from 2 parts warm, saline Slope Water with 1 part cold, fresh Scotian Shelf Water to a similar total transport made up of 2 parts Scotian Shelf Water and 1 part Slope Water. This large change in the relative contribution of the inflows would affect not only the salinity balance, but also the transport of nutrients, phytoplankton, and zooplankton contained in those 2 source waters. As suggested by Kane (2007), the greater contribution of water from the Scotian Shelf in the 1990s and the biological communities it contained was likely the primary cause of the decadal shift in zooplankton community structure. However, the salinity values in the 1980s and 1990s did exhibit considerable overlap (Figs. 2 \& 5), while the relationship of the zooplankton community to salinity switched between the 2 decades (i.e. the opposite slopes evident in Fig. 5). The processes underlying the zooplankton-salinity relationship were evidently different in the 2 decades. The different sources of the salinity variability in the 2 decades (Table 2) could be responsible for these different underlying processes linking to the zooplankton. In the 1990s, the salinity variability was caused primarily by changes in the inflow of Scotian Shelf waters (the advective source).
Similar to the assumed cause of the overall decadal shift in the zooplankton community structure, increased Scotian Shelf input would be associated with lower salinity and a shift to higher ZooX values, consistent with the 1990s relationship in Fig. 5. In the 1980s, the salinity variability was due largely to local sources (Table 2). In both decades, lower surface layer salinities, whatever the source, could have led to increased winter phytoplankton production, as suggested by Durbin et al. (2003) and Pershing et al. (2005), and enhanced the production of the locally dominant zooplankton community. This would have resulted in more negative ZooX values in the 1980s and enhanced the move to more positive ZooX values associated with advective forcing in the 1990s - in both cases consistent with the decadal relationships in Fig. 5. However, confirmation of these speculations on the processes responsible for the different relationships in Fig. 5 will require a more substantive analysis on a species and population specific basis.

The cause of the change around 1990 in the amounts of Scotian Shelf Water and Slope Water flowing into the GoM, with the associated decrease in mean salinity (Fig. 2), has not been identified, but likely has its origin outside of the local region. The North Atlantic Oscillation (NAO) is an index of largescale atmospheric forcing over the North Atlantic Ocean that has been related to many physical and biological changes around the North Atlantic basin (e.g. Hurrell et al. 2003). However, none of the time series considered here (salinity anomaly, ZooX, or recruits per hatch) shows any relation to the NAO index (for lags of 0,1 , or $2 \mathrm{yr}$ ). Brodziak \& O'Brien (2005) did find a significant relationship between GB cod recruitment and NAO with a 2 yr lag. However, they used a different indication of recruitment (recruits per spawner anomaly) and, more importantly, a longer time series (24 yr) than used here (13 yr), so they may have identified a relationship that the data sets used here were unable to detect. Large-scale changes in the northwest Atlantic Ocean salinity have been documented for the 1970s, 1980s, and 1990s, termed 'Great Salinity Anomalies' (GSAs; Belkin et al. 1998). The 1990s GSA is believed to have originated from melting in the Arctic and arrived in 2 pulses, the first traveling through the Canadian Archipelago around 1989 and the second taking a longer transit path through Fram Strait (Greene \& Pershing 2007). The propagation of these 2 pulses in the coastal current system from Labrador to the GoM may be responsible for the salinity shift around 1990 and the large salinity decrease in 1998 (Fig. 2; Greene \& Pershing 2007). The implication is that far distant environmental changes may have significant effects on the GoM/GB ecosystem. 
The estimates of cod and haddock survivorship were determined from egg hatching to recruitment at age 1 and so involve mortality during both the larval and juvenile stages. The juvenile stage $(\sim 8 \mathrm{mo})$ is much longer than the larval stage ( $\sim 1$ to $2 \mathrm{mo})$. Also, Mountain et al. (2008) showed that haddock larval mortality rates were higher than those for cod larvae during the 1995 to 1999 period, when the overall survivorship for haddock was about 2 to 3 times higher than that for cod (Fig. 6). Therefore, the changes in survivorship between the 1980s and 1990s are believed to reflect changes primarily during the juvenile stage, rather than the larval stage. The demersal juveniles of both species inhabit the same gravel areas on the northeastern edge of GB (Lough et al. 1989), which likely provide refuge from predation. The uniform survivorship of the combined population (Fig. 6) over the whole time series, including a possible density-dependent decrease at high population abundance, suggests an overall constraint on combined survivorship. The limited availability of food and/or of the preferred gravel habitat could represent such a constraint, with the species whose juveniles survived and grew large enough to first occupy that habitat having an advantage. In their overall diet, larval and juvenile haddock on GB favor smaller-sized prey organisms and exhibit less preference in prey species selection than do cod (Kane 1984, Auditore et al. 1994). Rowlands et al. (2008) reported that in the Irish Sea, cod exhibited a clear preference for Calanus spp. after metamorphosis, while haddock continued feeding on nauplii with little species preference later into their development. Beaugrand et al. (2003) showed a decrease in North Sea cod recruitment when the mean size of calanoid copepods decreased by a factor of 2 . On GB, the species that became dominant in abundance in the 1990s (e.g. Pseudocalanus spp., Centropages typicus, Temora longicornis, Oithina spp.; Kane 2007) all are less than half the size of the previously dominant Calanus (e.g. approximate adult weights of $0.013,0.042,0.013$, 0.002 vs. $0.190 \mathrm{mg}$, respectively). Given the feeding characteristics of the 2 species, this shift to smallersized zooplankton may have favored the growth and survival of haddock over that of cod. However, an analysis (not shown) of the young-of-the-year cod and haddock catches from the annual NEFSC fall trawl surveys did not indicate a change in size for either species between the 2 time periods, which might be expected if food availability and growth were major determinants of the changes in survivorship.

Cod and haddock are only 2 of many species that make up the fish complex on GB. Changes in the physical environment and lower trophic levels would be expected to affect other species as well. Link et al.
(2002) conducted a principal component analysis using a suite of biotic, abiotic, and human metrics for the northeast shelf ecosystem including the Mid-Atlantic Bight, GB, and the GoM over the period 1968 to 1999. Salinity and zooplankton parameters were not part of the analysis. The first 2 principal components, PC1 and PC2 (accounting for 30.8 and $16.7 \%$ of the variance, respectively), fell into 3 major groupings representing 3 time periods, 1968-1979, 1980-1989, and 19901999, with a plot of the 2 components (Fig. 6 of Link et al. 2002) being very similar to that for our zooplankton community analysis (Fig. 3). For the period common with the analysis presented here (1978 to 1999), the PC1 score exhibits a near-linear pattern with the ZooX time series $\left(\mathrm{R}^{2}=0.50, \mathrm{p}<0.001\right.$; Fig. 9). The variety of parameters and wider geographic coverage included in the analysis of Link et al. (2002) makes it difficult to draw specific biological conclusions from Fig. 9. However, the implication is that the ecosystem as a whole experienced major decadal-scale changes similar to the zooplankton and cod and haddock survival changes identified in this report.

Analyses like those presented here could be characterized as attempts to use short time series of simple parameters to reveal relationships between components of very complex ecosystems. As a result, while they may suggest intriguing and plausible relationships, these analyses generally lack the statistical power to confirm such relationships or the range of observations needed to identify the causal mechanisms responsible for them. Additional sampling, analysis, and modeling would be required. Such is the case here. Nevertheless, the co-occurrence of decadal-scale shifts in the salinity, zooplankton community, and first year fish survival is compelling. The changes in first year fish survival have important implications for fish-

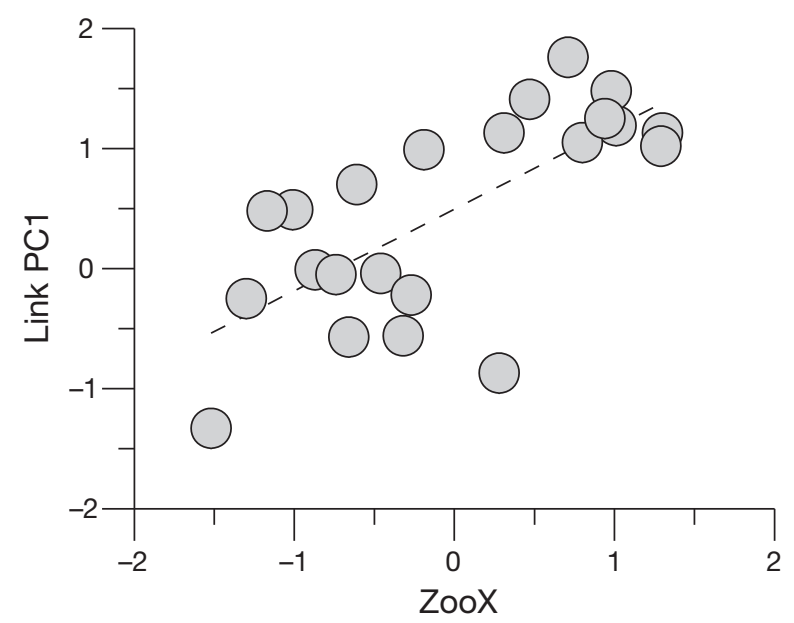

Fig. 9. Comparison of the first principal component from Link et al. (2002) and ZooX (from Fig. 3). Dashed line: significant linear regression 
ery management: a surviving egg contributed 2 or 3 times more to the population under one regime than under the other, implying different stock-recruitment relationships under the different regimes. The strong recovery of the haddock population on GB during the 1990s was likely due not only to targeted management measures, but also to ecosystem level changes that increased the first year survival of haddock. Similarly, the correspondingly slow recovery of cod was likely attributable, at least in part, to the same ecosystem changes favoring haddock survival over that of cod and a decrease in first year survival for cod. Understanding the connections between the physical water properties, the zooplankton community, and the first year fish survival would be critical for implementing a full ecosystem-based approach to regional fishery management.

Acknowledgements. We thank our many colleagues who spent months at sea and in the lab collecting and processing the data and samples used in these analyses. We also thank J. Hare and 5 anonymous reviewers for their thoughtful suggestions that improved the quality this manuscript. This work was supported in part through the US GLOBEC program and the NOAA/NMFS Fisheries and the Environment (FATE) program. This is US GLOBEC contribution 644.

\section{LITERATURE CITED}

Auditore PJ, Lough RG, Broughton EA (1994) A review of comparative development of Atlantic cod (Gadus morhua 1.) and haddock (Melanogrammus aeglefinus 1.) based on an illustrated series of larvae and juveniles from Georges Bank. Northwest Atl Fish Organ Sci Counc Stud 20:7-18

Beaugrand G, Brander KM, Lindley JA, Souissi S, Reid PC (2003) Plankton effect on cod recruitment in the North Sea. Nature 426:661-664

Belkin IM, Levitus S, Antonov J, Malmberg SA (1998) Great salinity anomalies in the North Atlantic. Prog Oceanogr 41:1-68

Brodziak J, O'Brien L (2005) Do environmental factors affect recruits per spawner anomalies of New England groundfish? ICES J Mar Sci 62:1394-1407

Brodziak J, Traver M, Col L, Sutherland S (2006). Stock assessment of Georges Bank haddock, 1931-2004. Northeast Fish Sci Cent Ref Doc 06-11. Available at: www. nefsc.noaa.gov/nefsc/publications/crd/crd0611/

> Durbin EG, Campbell RG, Casas MC, Ohman JD, Niehoff B, Runge J, Wagner M (2003) Interannual variation in phytoplankton blooms and zooplankton productivity and abundance in the Gulf of Maine during winter. Mar Ecol Prog Ser 254:81-100

Greene $\mathrm{CH}$, Pershing AJ (2007) Climate drives sea change. Science 315:1084-1085

> Houghton RW, Fairbanks RG (2001) Water sources for Georges Bank. Deep-Sea Res II 48:95-114

Hurrell JW, Kushnir Y, Ottersen G, Visbeck (eds) (2003) The North Atlantic Oscillation: climatic significance and environmental impact. Geophysical Monograph 134, American Geophysical Union, Washington, DC
Ji R, Davis CS, Chen C, Townsend DW, Mountain DG, Beardsley RC (2007) Influence of ocean freshening on shelf phytoplankton dynamics. Geophys Res Lett 34:L24607. doi:10.1029/2007GL032010

Kane J (1984) The feeding habits of co-occuring cod and haddock larvae from Georges Bank. Mar Ecol Prog Ser 16:9-20

Kane J (2007) Zooplankton abundance trends on Georges Bank, 1977-2004. ICES J Mar Sci 64:909-919

Link JS, Brodziak JKT, Edwards SF, Overholtz JW and others (2002) Marine ecosystem assessment in a fisheries management context. Can J Fish Aquat Sci 59:1429-1440

Lough RG, Valentine PC, Potter DC, Auditore PJ, Bolz GR, Neilson JD, Perry RI (1989) Ecology and distribution of juvenile cod and haddock in relation to sediment type and bottom currents on eastern Georges Bank. Mar Ecol Prog Ser 56:1-12

Lough RG, Smith WG, Werner FE, Loder JW and others (1994) Influence of wind-driven advection on interannual variability in cod egg and larval distributions on Georges Bank: 1982 vs 1995. ICES Mar Sci Symp 198:356-378

> Lough RG, Hannah CG, Berrien P, Brickman D, Loder JW, Quinlan JA (2006) Spawning pattern variability and its effect on retention, larval growth and recruitment in Georges Bank cod and haddock. Mar Ecol Prog Ser 310: $193-212$

> Meise-Munns C, Green J, Ingham M, Mountain D (1990) Interannual variability in the copepod populations of Georges Bank and the western Gulf of Maine. Mar Ecol Prog Ser 65:225-232

> Mountain DG (2003) Variability in the properties of shelf water in the Middle Atlantic Bight, 1977-1999. J Geophys Res 108(C1):3014 doi:10.1029/2001JC001044

Mountain DG (2004) Variability of the water properties in NAFO subareas 5 and 6 during the 1990s. J Northwest Atl Fish Sci 34:101-110

Mountain DG, Manning JP (1994) Seasonal and interannual variability in the properties of the surface waters of the Gulf of Maine. Cont Shelf Res 14:1555-1581

Mountain D, Green J, Sibunka J, Johnson D (2008) Growth and mortality of Atlantic cod Gadus morhua and haddock Melanogrammus aeglefinus eggs and larvae on Georges Bank, 1995-1999. Mar Ecol Prog Ser 353:2 25-242

O'Brien L, Shepherd N, Col L (2006) Assessment of the Georges Bank Atlantic cod stock for 2005. Northeast Fish Sci Cent Ref Doc 06-10. Available at: www.nefsc.noaa. gov/nefsc/publications/crd/crd0610/

Page FH, Frank KT (1989) Spawning time and egg stage duration in Northwest Atlantic haddock (Melanogrammus aeglefinus) stocks with emphasis on Georges and Browns Bank. Can J Fish Aquat Sci 46 (Suppl 1):68-81

> Pershing AJ, Greene CH, Jossi JW, O'Brien L, Brodziak JKT, Bailey BA (2005) Interdecadal variability in the Gulf of Maine zooplankton community, with potential impacts on fish recruitment. ICES J Mar Sci 62:1511-1523

Rowlands WL, Dickey-Collas M, Geffen AJ, Nash RDM (2008) Diet overlap and prey selection through metamorphosis in Irish Sea cod (Gadus morhua), haddock (Melanogrammus aeglefinus), and whiting (Merlangius merlangus). Can J Fish Aquat Sci 65:1297-1306

Sherman K (1980) MARMAP, a fisheries ecosystem study of the Northwest Atlantic fluctuations in ichthyoplanktonzoolankton components and their potential for impact on the system. In: Diemer FP, Vernberg FJ, Mirkes DZ (eds) Advanced concepts in ocean measurements for marine biology. Belle W Baruch Inst Mar Biol Coast Res. University of South Carolina Press, Columbia, SC, p 3-37 
Smith PC, Houghton RW, Fairbanks RG, Mountain DG (2001) Interannual variability of boundary fluxes and water mass properties in the Gulf of Maine and on Georges Bank: 1993-97. Deep-Sea Res II 48: 37-70

Syrjala S (2000) Critique on the use of the delta distribution for the analysis of trawl survey data. ICES J Mar Sci 57: 831-842

Taylor MH, Mountain DG (2009) The influence of surface layer salinity on wintertime convection in

Editorial responsibility: William Peterson,

Newport, Oregon, USA
Wilkinson Basin, Gulf of Maine. Cont Shelf Res 29: $433-444$

US GLOBEC (1992) Northwest Atlantic implementation plan for the Georges Bank Study. Rep No 6, GLOBEC. (www.usglobec.org/reports.php)

Werner FE, Page FH, Lynch DR, Loder JW and others (1993) Influences of mean advection and simple behavior on the distribution of cod and haddock early life stages on Georges Bank. Fish Oceanogr 2:43-64

Submitted: April 7, 2009; Accepted: September 4, 2009 Proofs received from author(s): November 29, 2009 